\title{
ITINERÁRIOS FORMATIVOS: DA BASE NACIONAL COMUM CURRICULAR (BNCC) ÀS PRÁTICAS DO PROFESSOR DE MATEMÁTICA
}

\section{ARTIGO ORIGINAL}

SILVA, Eder Anelli da ${ }^{1}$, MACIEL, Maria Delourdes ${ }^{2}$

SILVA, Eder Anelli da. MACIEL, Maria Delourdes. Itinerários Formativos: da Base Nacional Comum Curricular (BNCC) às práticas do professor de matemática. Revista Científica Multidisciplinar Núcleo do Conhecimento. Ano. 06, Ed. 12, Vol. 03, pp. 68-79. Dezembro de 2021. ISSN: 2448-0959, Link de acesso: https://www.nucleodoconhecimento.com.br/educacao/itinerarios-formativos, DOI: 10.32749/nucleodoconhecimento.com.br/educacao/itinerarios-formativos

\section{RESUMO}

Percebe-se que os avanços da educação estão cada vez mais relacionados aos documentos que promulgam os Direitos Humanos e o Desenvolvimento Sustentável, como apresentados na Declaração Universal dos Direitos Humanos e nos Objetivos do Desenvolvimento Sustentável, aplicáveis às novas propostas para o Ensino Médio, dimensionadas por meio de Itinerários Formativos que integram as diferentes áreas de conhecimento, bem como as competências e habilidades no Ensino da Matemática. Assim, questiona-se: como se dá a integração da Matemática com os itinerários formativos e como ela impacta a prática do professor em sala de aula? $\mathrm{O}$ objetivo geral deste estudo foi compreender de que forma ocorre a integração da Matemática com os itinerários formativos propostos pela BNCC. Para tanto, recorreu-se a metodologia qualitativa do tipo documental, tendo como objeto de

\footnotetext{
${ }^{1}$ Mestrando em Ensino de Ciências - Universidade Cruzeiro do Sul. Especialista em Controladoria e FinançasUniversidade Cruzeiro do Sul. Licenciatura em Matemática - Universidade Cruzeiro do Sul. Licenciatura em Filosofia - Universidade Cruzeiro do Sul. Bacharel em Ciências Contábeis - Universidade Cruzeiro do Sul. ORCID: https://orcid.org/0000-0002-5350-2034.

${ }^{2}$ Orientadora. ORCID: https://orcid.org/0000-0002-6821-5185.
}

RC: 102896

Disponível em: https://www.nucleodoconhecimento.com.br/educacao/itinerariosformativos 
análise os itinerários formativos propostos na BNCC para o Ensino Médio. Os resultados apontam os possíveis impactos desses Itinerários sobre a prática do professor. Compreende-se a essencialidade dos estudos nas diferentes áreas, entre elas a Matemática, envolvendo habilidades e competências integradas, o que influencia diretamente a prática do professor em sala de aula. Destaca-se a sua importância no quesito de transformação social, contudo é preciso considerar a necessidade de reformulações nas formações direcionadas aos professores da Escola Básica, de modo que os itinerários formativos possam ser implementados de forma efetiva e que faça sentido aos alunos.

Palavras-Chave: Itinerário Formativo, Base Nacional Comum Curricular (BNCC), Matemática, Práticas Docentes, Ensino Médio.

\section{INTRODUÇÃO}

Ao longo da história, diversos foram os processos que contribuíram para as mudanças sociais, tanto no contexto mundial quanto do Brasil.

Ao se pensar sobre a importância da Declaração Universal dos Direitos Humanos deve-se considerar que essa está inserida em todos os campos de estudo e, por isso, deve ser também considerada no desenvolvimento de propostas que promovam alterações no sistema de educação nacional, como a Reforma do Ensino Médio atualmente em implementação no Brasil, que traz a inserção de itinerários formativos no processo de ensino aprendizado das diferentes áreas. Neste contexto, o presente artigo, tem como questão norteadora: como se dá a integração da Matemática com os itinerários formativos e como ela impacta a prática do professor em sala de aula?

Nessa perspectiva, o objetivo geral do estudo foi compreender de que forma ocorre a integração da Matemática com os itinerários formativos, tendo por especificidade seus impactos na prática do professor em relação a sua interação em sala de aula. 
Devido a implementação dos itinerários formativos estar em andamento, a metodologia empregada foi de caráter documental, visando um melhor entendimento de seu funcionamento, como previsto nos documentos (GIL, 2008). Para entender as ações sociais que os estudos por itinerário formativo permitirão, além de transformar o desenvolvimento pessoal e profissional dos alunos, é preciso investigar considerando todos os aspectos envolvidos e que fazem parte da construção de sua cidadania.

Foram considerados os documentos oficiais como base de análise e de estudo para compreensão das alterações realizadas no Ensino Médio, e a inserção de itinerários formativos que visam contribuir para a integração das áreas de ensino, principal fato reformulador do sistema de ensino desse nível.

Assim, este artigo foi organizado a partir da apresentação de um contexto que relaciona a Declaração Universal dos Direitos Humanos (DUDH), os Objetivos de Desenvolvimento Social (ODS) e a Base Nacional Comum Curricular (BNCC). Em seguida, foi evidenciada a integração da área Matemática e suas Tecnologias com os itinerários formativos e a integração das competências na prática do professor.

Desse modo, acredita-se que será possível compreender a relação dos documentos DUDH e ODS na construção da BNCC e na proposta dos itinerários formativos, considerando seus impactos na prática do professor em sala de aula, que é o objetivo desse artigo. Por meio das integrações, entende-se que poderá ser mais bem compreendido como se dá esse desenvolvimento.

\section{CONTEXTO DA DECLARAÇÃO UNIVERSAL DOS DIREITOS} HUMANOS E SUA RELAÇÃO COM OS OBJETIVOS DE DESENVOLVIMENTOS SUSTENTÁVEL E BASE NACIONAL COMUM CURRICULAR

Em 1946 a Organização das Nações Unidas (ONU), elabora a Declaração Universal dos Direitos Humanos (DUDH) idealizada pelos EUA, Taiwan, Reino Unido, URSS, 
Canadá, Chile, França, Austrália e Líbano, países membros do comitê responsável pelos assuntos relacionados aos Direitos Humanos (ONU, 1948).

A DUDH, composta por 30 artigos, foi assinada por 51 países e passou a vigorar no ano de 1948 (ONU, 1948).

Em 2012, a partir da Conferência ocorrida no Rio de Janeiro, a ONU organizou os Objetivos de Desenvolvimento Sustentável (ODS), um documento que contém um conjunto de elementos com vistas a orientar governos, empresas e sociedades em relação a ações de busca por um mundo sustentável e inclusivo, além de superar as urgências voltadas para políticas ambientais e econômicas. Este documento substitui os Objetivos de Desenvolvimento do Milênio, adaptando aqueles que não foram atingidos e ramificando os objetivos do atual documento em 169 metas que devem ser atingidas até 2030 (ONU, 2012).

Diversos elementos presentes na DUDH e ODS foram contemplados na Base Nacional Comum Curricular (BNCC), estruturada de acordo com os níveis de ensino e etapas que fazem parte da Educação Básica brasileira.

A BNCC propõe o desenvolvimento de competências significativas que tratam não apenas dos conteúdos de ensino de sala de aula, mas de vários elementos que auxiliam na formação do aluno como cidadão. A BNCC (BRASIL, 2018), alinhada com as promulgações da ONU para um mundo melhor, elencou dez competências para assegurar o direito de aprendizagem do aluno, além de firmar valores que estimulem a sua transformação social e humana.

No Ensino Médio, na área da Matemática e suas Tecnologias, têm-se 5 competências que se relacionam com eixos que podem ser trabalhados com os alunos do $1^{\circ}$ ao $3^{\circ}$ ano.

Destaca-se a competência de número 1, que consiste em saber utilizar conhecimentos matemáticos para interpretar diferentes situações cotidianas e fatos presentes no contexto das Ciências da Natureza e Humanas, e no contexto das 
questões socioeconômicas e/ou tecnológicas, a fim de contribuir para uma formação completa (BRASIL, 2018).

Segundo a BNCC, é possível trabalhar contextos que estejam relacionados ao cotidiano e vivência do aluno, inter-relacionando assuntos a partir de conceitos matemáticos que dialoguem com outras áreas de ensino, tais como Ciências humanas e Ciências da Natureza ou Linguagens.

Com enfoque na construção de cidadãos críticos, no desenvolvimento do pensamento e na capacidade de análise do estudante perante os fatos cotidianos, o atual modelo de ensino abandona a simples reprodução de conteúdos ou temas específicos das áreas e assume a proposta de formação de um aluno capaz de protagonizar seu aprendizado e poder atuar no seu dia a dia.

O artigo 19 da DUDH trata do direito à liberdade de opinião e expressão. Quando falamos de educação e ensino, essa liberdade de expressão é relevante e necessária para que o aluno possa construir seu pensamento de mundo, agregar outros valores para si, além daqueles de sua família, podendo, também, ensinar com o aprendizado obtido (ONU, 1948).

Essa liberdade de expressão permite, ainda, o diálogo entre professor e aluno de forma flexível, para que opiniões não se tornem dogmas e sejam reduzidas a leis que não existem. Toda pessoa tem direito à liberdade de opinião e expressão; esse direito inclui a liberdade de, sem interferência, ter opiniões e de buscar, receber e transmitir informações e ideias por qualquer meio e independentemente de fronteiras (ONU, 1948).

É interessante observar o quão importante a informação é para o convívio social, tornando a população detentora de elementos que a faz refletir e tomar decisões necessárias e conscientes, papel esse que a Matemática deve assumir para com todos os estudantes no seu dia a dia, estando presente em diversos contextos, desde um simples cálculo diário até a interpretação de gráficos e dados, muitas 
vezes distorcidos por quem os veicula. Esta visão social da Matemática está prevista nos Itinerários Formativos propostos na BNCC.

\section{INTEGRAÇÃO DA ÁREA DE MATEMÁtICA E SUAS TECNOLOGIAS COM OS ITINERÁRIOS FORMATIVOS PROPOSTOS NA BASE NACIONAL COMUM CURRICULAR (BNCC)}

Assegurando direitos de aprendizagem e a transformação social e humana do aluno, a BNCC ao propor suas dez competências para a educação básica, busca evidenciar o protagonismo do aluno e sua interação, via mediação do professor, de modo a construir seus pensamentos reflexivos e uma visão crítica sobre o mundo em que está inserido.

Ao longo da Educação Básica, as aprendizagens básicas estabelecidas pela BNCC devem garantir o desenvolvimento das dez competências gerais que, no contexto pedagógico, consolidam os direitos de aprendizagem e desenvolvimento do aluno (BRASIL, 2018).

Nessa visão de aluno ativo em seu aprendizado e em busca de seus direitos de desenvolvimento, as competências se inter-relacionam e tratam de seus temas e conteúdo de modo que o aluno, ao passar pelas etapas de ensino que compõem o sistema de educação brasileiro, possam construir seus conhecimentos e desenvolver habilidades para a formação de atitudes e valores (BNCC, 2018).

Considerando as dez competências gerais, destaca-se a de número 2, que consiste em desenvolver a curiosidade intelectual e utilizar a abordagem própria das ciências, como "a investigação, a reflexão, a análise crítica, a imaginação e a criatividade, para investigar causas, elaborar e testar hipóteses, formular e resolver problemas e criar soluções (inclusive tecnológicas) com base nos conhecimentos das diferentes áreas" (BRASIL, 2018, p. 9). Esta é uma competência de grande importância para o desenvolvimento do pensamento científico e que pode e deve ser trabalhada em diversas áreas. 
Quando inserida na área de Matemática e suas Tecnologias, esta competência geral no 2 ganha ênfase no trabalho com conceitos que permitam ao estudante testar hipóteses e elaborar formulações para a obtenção de resultados que impactem diretamente a sociedade, seja no todo ou em parcela específica.

Vale ressaltar que a Matemática, além de ser uma área de conhecimento, também configura um itinerário formativo que visa, conforme BNCC (2018), a flexibilização estratégica da organização curricular, focando em sua área de conhecimento. Assim, ao falar de Matemática, temos na BNCC:

[...] aprofundamento de conhecimentos estruturantes para aplicação de diferentes conceitos matemáticos em contextos sociais e de trabalho, estruturando arranjos curriculares que permitam estudos em resolução de problemas e análises complexas, funcionais e não-lineares, análise de dados estatísticos e probabilidade, geometria e topologia, robótica, automação, inteligência artificial, programação, jogos digitais, sistemas dinâmicos, dentre outros, considerando o contexto local e as possibilidades de oferta pelos sistemas de ensino (BRASIL, 2018).

Nessa relação, é possível compreender o quão importante é a investigação como estratégia de ensino proposta na competência geral de número 2 , que a enfatiza no itinerário formativo proposto, para que o aluno possa aplicar diferentes conceitos matemáticos em diversos aspectos da análise.

É necessário que o estudante tenha a compreensão de como poderá desenvolver seus conhecimentos e pensamentos críticos diante dos fatos observados. Isso não dependerá apenas do aprendizado teórico construído ao longo de seu ciclo acadêmico, mas do desenvolvimento de diversos contextos abordados nas diferentes áreas do conhecimento o que permitirá a aplicação direta dos conceitos matemáticos.

As competências básicas são diretamente integradas pela BNCC (2018) nas áreas de conhecimento e nos itinerários formativos específicos, de modo que independente do nível de ensino em que esteja, o aluno possa desenvolver seu pensamento crítico de acordo com sua faixa etária e desenvolva sua compreensão 
de mundo. No Ensino Médio o aluno poderá entender de fato e de forma prática a sua aplicação na sociedade.

\section{INTEGRAÇÃO DAS COMPETÊNCIAS E HABILIDADES MATEMÁTICAS COM A PRÁTICA DA SALA DE AULA E A INTERAÇÃO DO PROFESSOR}

Considerando a BNCC, observa-se que a disciplina de Matemática é a única isolada e configurada como uma grande área, com o itinerário formativo denominado Matemática e suas Tecnologias, para trabalhar seu vasto currículo ao longo dos três anos que integram o Ensino Médio. $O$ fato de ser uma disciplina isolada não desmerece sua importância, pois é visível a extensão e complexidade de sua estruturação em meio aos conteúdos que devem ser trabalhados. Logo, sua organização é determinada por competências e habilidades que visam a vivência cotidiana do aluno para que, conforme BNCC (BRASIL, 2018), possam utilizar recursos tecnológicos que trabalhem a investigação matemática e, ao mesmo tempo, desenvolvam o pensamento computacional.

Visando a aquisição dessas competências e habilidades no ciclo de estudos do Ensino Médio, o trabalho colaborativo entre professor e aluno se torna essencial, pois o docente sendo mediador do processo de aprendizado, permite que o aluno possa inserir-se no meio e trazer para o contexto o que vivencia em seu cotidiano, compreendendo a aplicação efetiva do conteúdo abordado e tornando-se protagonista de seu processo de aprendizagem.

Com a finalidade de compreender de forma mais prática como se dá essa integração das competências e habilidades com a interação professor versus aluno, listamos três propostas de atividades relacionadas ao ensino de Matemática no Ensino Médio (Quadro 1): 
Quadro 1 - Proposta de atividade para o $1^{\circ}$ e $2^{\circ}$ ano do Ensino Médio

\section{TEMA Profissões: em que área me encontro?}

COMPETÊNCIA Específica 3: Utilizar estratégias, conceitos, definições e (BNCC) procedimentos matemáticos para interpretar, construir modelos e resolver problemas em diversos contextos, analisando a plausibilidade dos resultados e a adequação das soluções propostas, de modo a construir argumentação consistente.

HABILIDADES (EM13MAT301) Resolver e elaborar problemas do cotidiano, da (BNCC) Matemática e de outras áreas do conhecimento, que envolvem equações lineares simultâneas, usando técnicas algébricas e gráficas, com ou sem apoio de tecnologias digitais. (EM13MAT312) Resolver e elaborar problemas que envolvem o cálculo de probabilidade de eventos em experimentos aleatórios sucessivos.

PROPOSTA Cada aluno irá indicar qual carreira pretende seguir e profissão idealizada. Após isso, cada uma das profissões será segmentada em acordo com as 4 áreas de conhecimento e calculados seus percentuais e variações. Será construída uma situação problema, com auxílio de gráficos de funções e cálculos probabilísticos sobre essas atuações.

Fonte: dados da pesquisa.

Com a proposta apresentada no quadro 1, a interação professor versus aluno ocorre desde o início da atividade, com o levantamento das informações, tendo o discente como protagonista desde o primeiro momento, pois é ele quem conduzirá toda a atividade, havendo um trabalho colaborativo. O papel do docente será de mediador, questionando hipóteses e apresentando situações conforme as informações inseridas pelos alunos (Quadro 2). 
Quadro 2 - Proposta de atividade para o 3ํano do Ensino Médio

\begin{tabular}{|c|c|}
\hline TEMA & Incógnitas, Planos ou Porcentagens? \\
\hline $\begin{array}{l}\text { COMPETÊNCIA } \\
\text { (BNCC) }\end{array}$ & $\begin{array}{l}\text { Específica 4: Compreender e utilizar, com flexibilidade e } \\
\text { precisão, diferentes registros de representação matemáticos } \\
\text { (algébrico, geométrico, estatístico, computacional etc.), na } \\
\text { busca de solução e comunicação de resultados de problemas. }\end{array}$ \\
\hline & $\begin{array}{l}\text { (EM13MAT401) Converter representações algébricas de } \\
\text { funções polinomiais de 1arau em representações geométricas } \\
\text { no plano cartesiano, distinguindo os casos nos quais o } \\
\text { comportamento é proporcional, recorrendo ou não a softwares } \\
\text { ou aplicativos de álgebra e geometria dinâmica. } \\
\text { (EM13MAT406) Construir e interpretar tabelas e gráficos de } \\
\text { frequências com base em dados obtidos em pesquisas por } \\
\text { amostras estatísticas, incluindo ou não o uso de softwares que } \\
\text { inter-relacionem estatística, geometria e álgebra. }\end{array}$ \\
\hline PROPOSTA & $\begin{array}{l}\text { A partir de expressões algébricas, os alunos terão de elaborar } \\
\text { planos cartesianos e ou dados estatísticos que apresentem } \\
\text { solução efetiva para as situações problemas apresentados. A } \\
\text { turma será dividida em grupos de } 4 \text { alunos e cada grupo terá } \\
\text { duas situações problemas para resolver. O professor passará } \\
\text { entre os grupos para retirar dúvidas e provocar reflexões que } \\
\text { auxiliem o aluno na construção do pensamento matemático } \\
\text { solicitado. Ao final, cada grupo apresentará para turma o } \\
\text { raciocínio desenvolvido. }\end{array}$ \\
\hline
\end{tabular}

Fonte: dados da pesquisa.

A atividade proposta no quadro 2 se configura como um trabalho colaborativo entre os colegas de sala, com mediação do professor e interferência nos raciocínios, a fim de mostrar ao aluno vertentes que possam fazer com que ele reflita sobre o mesmo exercício em diversos aspectos (Quadro 3).

RC: 102896

Disponível em: https://www.nucleodoconhecimento.com.br/educacao/itinerariosformativos 
Quadro 3 - Proposta de atividade para o 3ํano do Ensino Médio

\begin{tabular}{|l|l|}
\hline TEMA & Há regularidade nos cômodos de minha casa? \\
\hline COMPETENNCIA & $\begin{array}{l}\text { Específica 5: Investigar e estabelecer conjecturas a respeito de } \\
\text { diferentes conceitos e propriedades matemáticas, empregando } \\
\text { estratégias e recursos, como observação de padrões, } \\
\text { experimentações e diferentes tecnologias, identificando a } \\
\text { necessidade, ou não, de uma demonstração cada vez mais } \\
\text { formal na validação das referidas conjecturas. }\end{array}$ \\
\hline HABILIDADES & $\begin{array}{l}\text { (EM13MAT505) Resolver problemas sobre ladrilhamento do } \\
\text { plano, com ou sem apoio de aplicativos de geometria } \\
\text { dinâmica, para conjecturar a respeito dos tipos ou composição } \\
\text { de polígonos que podem ser utilizados em ladrilhamento, } \\
\text { generalizando padrões observados. }\end{array}$ \\
\hline PROPOSTA & $\begin{array}{l}\text { O aluno deverá criar uma espécie de planta da sua casa e } \\
\text { mensurar cada metragem do comprimento de seus cômodos } \\
\text { (trabalhar apenas com uma dimensão, visto analisar figuras } \\
\text { planas). A partir dessas medidas, o aluno deverá analisar se há } \\
\text { regularidade nas mensurações levantadas e se de fato aquele } \\
\text { cômodo representa um polígono regular, problematizando a } \\
\text { situação, com questionamentos e respostas próprias. Deverão } \\
\text { apresentar para a turma, com o professor mediando a } \\
\text { discussão sobre as análises levantadas. }\end{array}$ \\
\hline (BNC)
\end{tabular}

Fonte: dados da pesquisa.

A construção da situação problema pelo próprio aluno demonstra o protagonismo deste em seu processo de aprendizagem e o trabalho colaborativo, pois ao apresentar suas análises para a turma, conforme a proposta do quadro 3, o aluno poderá questionar seus colegas e professor sobre a regularidade de tal figura, além de discutir sobre sua configuração como polígono ou não. Aqui há uma contextualização da vivência do aluno (sua casa) para com o conteúdo da disciplina. 
Em suma, trabalhar as competências propostas na BNCC (2018) para a área da Matemática e suas Tecnologias, no Ensino Médio, observando o contexto de vivência do aluno e promovendo atividades em que seu protagonismo é evidenciado, permite um trabalho colaborativo entre professor e aluno, além de promover um desenvolvimento competente e que, de fato, habilite o estudante diante do conteúdo estudado.

\section{CONSIDERAÇÕES FINAIS}

Este estudo refere-se aos itinerários formativos, a uma temática recentemente inserida na Educação Básica, no Ensino Médio, e que provoca uma reflexão acerca das efetivas mudanças a serem implementadas, as quais, se inseridas da forma pensada e observando as situações de cada região e público-alvo, poderão contribuir para uma transformação social e ascensão educacional.

Retomando a questão norteadora: como se dá a integração da Matemática com os itinerários formativos e como ela impacta a prática do professor em sala de aula? Concluímos que é perceptível que a integração da Matemática com os itinerários formativos possibilita ao aluno compreender e aprofundar conhecimentos desta área, de modo que o contexto seja inserido em sua regionalidade e vivências sociais, provocando uma prática docente mais interativa e perspicaz e que permita ao aluno compartilhar experiências reais e aplicáveis ao cotidiano do discente, o qual passa a protagonizar seu processo de ensino aprendizado.

Analisar documentos que historicamente contribuíram para a construção do que hoje é conhecido como sistema de ensino é algo importante para uma reflexão e compreensão daquilo que, de fato, possa ser considerado como uma inovação educacional ou mesmo de algo que já ocorre e não faz mais efeito na sociedade.

Trazer para a reflexão a Declaração Universal dos Direitos Humanos (DUDH) em paralelo com as ODS (Objetivos de Desenvolvimentos Sustentáveis), permitiu compreender quais direitos já promulgados ainda não estão, de fato, sendo 
concretizados na sociedade, seja por legislações repressoras ou que simplesmente não saíram do papel. Entender onde e como o comportamento social pode ser mudado, transformado e reconfigurado em busca de um mundo que entenda a importância da liberdade humana e atenda as suas necessidades, de modo a promover um mundo mais justo, inclusivo e que promova a cidadania nas nações pela igualdade, mesmo estando inserida em uma diversidade cultural, social, econômica, etc., é fundamental.

Relacionar elementos desses documentos com a Base Nacional Comum Curricular (BNCC), nada mais é que promover a mudança social pela educação, que é o verdadeiro caminho para essa perspectiva ideal. Retomando a questão norteadora deste estudo: como se dá a integração da Matemática com os itinerários formativos e como ela impacta a prática do professor em sala de aula, percebe-se que ao construir um itinerário das áreas, pensando em um ensino formativo e integrado, a Matemática passa a fazer sentido ao aluno e um fator de importante transformação social, visto torná-lo protagonista de seu ensino-aprendizado e permitir que o mesmo construa sua cidadania a partir da vivência de situações nas quais já está inserido em seu cotidiano e região. As ações do professor também são transformadas, pois cada vez mais devem compreender e aplicar as necessidades e experiências que os alunos trazem para a sala de aula, de modo a integrar os conhecimentos e levar aos discentes, maneiras de inserir tal aprendizado em sua vida cotidiana, seja pessoal ou profissional. Assim, a formação do professor deve, cada vez mais, ser aperfeiçoada e integrada as demais áreas, trazendo um ensino efetivo e que promova, de fato, uma transformação social.

Nessa perspectiva, vale um aprofundamento em pesquisa futura, pensando como as formações de professores deverão ocorrer a partir da implementação dessa reforma do Ensino Médio e compreensão de ensino por meio de itinerário formativo, visando aspectos que farão a diferença para que o professor, em sala de aula, possa promover um ensino transformador e integrado as áreas e aos alunos.

RC: 102896

Disponível em: https://www.nucleodoconhecimento.com.br/educacao/itinerariosformativos 


\section{REFERÊNCIAS}

BRASIL. Ministério da Educação. Base Nacional Comum Curricular. Brasília, 2018.

GIL, Antonio Carlos. C. Métodos e Técnicas de pesquisa social. 6 ed. São Paulo: Editora Atlas, 2008, $216 \mathrm{p}$.

ONU. Organização das Nações Unidas. Declaração universal dos direitos humanos. 1948. Disponível em <https://www.unicef.org/brazil/declaracao-universaldos-direitos-humanos >. Acesso em 01 Ago. 2021.

ONU. Organização das Nações Unidas Objetivos de desenvolvimento sustentável. 2012. Disponível em <https://brasil.un.org/pt-br/sdgs>. Acesso em 01 Ago. 2021.

Enviado: Novembro, 2021.

Aprovado: Dezembro, 2021. 